\title{
Taxas de Passagem e Cinética da Degradação Ruminal em Bezerros Holandeses Alimentados com Dietas Contendo Diferentes Níveis de Concentrado
}

\author{
Peter Johann Bürger ${ }^{2}$, José Carlos Pereira ${ }^{3}$, José Fernando Coelho da Silva ${ }^{3}$, Sebastião de \\ Campos Valadares Filho ${ }^{3}$, Paulo Roberto Cecon ${ }^{4}$, Cláudio Pereira Jordão ${ }^{5}$, Sérgio Pereira Braz ${ }^{6}$
}

RESUMO - Este trabalho foi realizado para avaliar os efeitos de diferentes níveis de concentrado sobre as taxas de passagem de fluidos, usando Co-EDTA, e partículas, usando cloreto de Iterbio e Cr-mordante e, a cinética da degradação ruminal in situ da matéria seca (MS) e da proteína bruta (PB). Cinco bezerros holandeses, inteiros, fistulados no rúmen e abomaso, com idade de 5,8 $\pm 0,7$ meses e de e 107,4 $\pm 11,0 \mathrm{~kg}$ $\mathrm{PV}$ médio inicial, foram distribuídos a um delineamento em quadrado latino $5 \mathrm{x} 5$ (tratamento $\mathrm{x}$ período). Os animais foram alojados em baias individuais e alimentados à vontade com dietas contendo 30,0;45,0; 60,0; 75,0; e 90,0\% de concentrado, com base na MS, em rações contendo como volumoso, o feno de capim coast-cross e no concentrado, o farelo de sojae, fubá de milho. A taxa de passagem de fluidos apresentou comportamento quadrático, estimando-se o valor máximo de $9,73 \% / \mathrm{h}$, com nível de $61,99 \%$ de concentrado na ração. A taxa de passagem de partículas do farelo de soja no retículo-rúmen- diminuiu linearmente, enquanto no ceco-cólon proximal não foi influenciada pelos níveis de concentrado na rações. As taxas de passagem do feno de capim coast-cross no rúmen-retículo e no ceco-cólon proximal não foram influenciadas pelo aumento no nível de concentrado nas rações. A degradação efetiva da MS do farelo de soja não foi influenciada, enquanto a do fubá de milho aumentou e do feno de capim coast-cross reduziu linearmente, respectivamente. A degradação efetiva da PB do farelo de soja e do feno de capim coast-cross não variou, porém a do fubá de milho aumentou linearmente, com o aumento dos níveis de concentrado nas rações.

Palavras-chave: bezerros holandeses, degradação ruminal, níveis de concentrado, taxa de passagem

\section{Passage Rates and Ruminal Degradation Kinetics in Holstein Calves Fed Diets with Different Concentrate Levels}

\begin{abstract}
This work was conducted to evaluate the effects of different concentrate levels on the liquid passage rates, using Co-EDTA, and particulate, using ytterbium chloride and Cr-mordant, and the in situ ruminal degradation kinetics of dry matter (DM) and crude protein (CP). Five rumen and abomasum fistulated bull Holstein calves, with an initial average age of $5.8 \pm 0.7$ months and initial average of $107.4 \pm 11.0 \mathrm{~kg} \mathrm{LW}$ were allotted to a $5 \times 5$ Latin square design (treatment $\mathrm{x}$ period). The animals were housed in individual stalls and full fed diets (DM basis) containing 30.0, 45.0, 60.0, 75,0 and 90.0\% of concentrate. The diets were based on coast-cross grass hay as forage and soybean meal an corn ground grain in the concentrate. The passage rate of fluids showed a quadratic behavior, with the maximum value of $9.73 \% / \mathrm{h}$, with the $61.69 \%$ of concentrate in the diet. The particulate passage rate of the soybean meal in the reticulumrumen linearly decreased, while the concentrate levels in the diets did not affect the passage rate in proximal cecum-colon. The concentrate levels in the diet did not affect the passage rates of the coast-cross grass hay in the reticulum-rumen and in the proximal cecum-colon. The effective degradation of the DM of the soybean meal was not affected, while those of the corn ground grain increased and coastcross grass hay linearly decreased, respectively. The effective degradation of the CP of the soybean meal and coast-cross grass hay did not vary, however, that of the corn ground grain linearly increased as the dietary concentrate levels increased.
\end{abstract}

Key Words: Holstein calves, ruminal degradation, concentrate levels, passage rate

\section{Introdução}

A taxa de passagem ou de trânsito refere-se ao fluxo de resíduos não-digeridos através do trato digestório; o fluxo ruminal inclui, além da fibra indigestível, bactérias e outras frações não-degradadas do alimento, sendo que a composição e o volume da dieta são variáveis externas que influenciam a digestão, a taxa de digestão e a reciclagem do conteúdo ruminal (VAN SOEST,1994).

Os fatores que influenciam a taxa de passagem da fase líquida, segundo OWENS e GOETSCH (1986), são o nível de ingestão, a proporção de concentrado, o indicador utilizado, bem como os

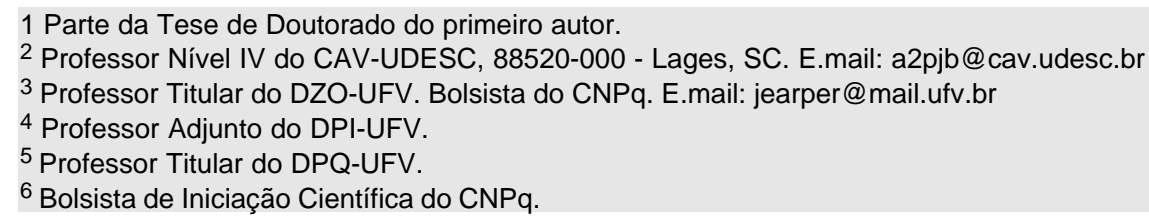


locais de amostragem. UDEN et al. (1980) propuseram o uso do Co-EDTA como indicador da fase líquida e concluíram que este apresenta boa recuperação, sendo válido para este tipo de estudo.

ELLIS et al. (1984) afirmaram que um indicador apropriado deve se comportar exatamente como a partícula alimentar, não alterando o processo normal de mistura e fluxo. Para estimar o fluxo da fração não-digerida através do compartimento, o indicador deve aderir à partícula do resíduo indigerido e não influenciar o fluxo da partícula marcada, comparada à não-marcada.

GALLOWAY et al. (1993), que testaram fenos de capim coast-cross (Cynodon dactilum, L. Pers.) e capim-dos-pomares (Dactilys glomerata) suplementados com concentrado à base de fubá de milho e casca de soja, em bezerros holandeses com pesos vivos iniciais de $210 \pm 9,2$ e $269 \pm 9,4 \mathrm{~kg}$, constataram que esses animais apresentaram taxa de passagem de partículas, respectivamente, de 4,18 e 4,80\%/h.

LOPEZ-GUISA e SATTER (1991), trabalhando com novilhas holandesas com peso médio de $414 \mathrm{~kg}$, alimentadas com feno de alfafa e resteva de milho, combinados do farelo de glúten de milho e resíduo de cervejaria, verificaram que os tempos de retenção da fase líquida estimados com Co-EDTA e Cr-EDTA foram similares (16,2 a 16,9 horas). O tempo de retenção de líquidos diferiu para o feno de alfafa e a resteva de milho (14,1 e 18,9 horas, respectivamente). O tempo de retenção ruminal foi similar, quando se compararam indicadores, samário e cério, respectivamente, 24,9 a 26,3 horas. O tempo de retenção total foi mais elevado para a resteva de milho do que para o feno (57,8 e 48,8 horas). O tempo médio de retenção obtido com o lantânio e itérbio foi similar, quando aplicado ao farelo de glúten de milho e aos resíduos de cervejaria (26,3 e 26,8 horas).

Segundo OSPINA (1995), na técnica in situ, o nível de concentrado da dieta, alterando as características físicas do conteúdo ruminal, pode provocar a obliteração dos poros dos sacos de náilon. Nas situações em que os animais são alimentados com dietas à base de volumosos, o material fibroso contido no rúmen exerce ação abrasiva sobre os poros, evitando sua obstrução.

CARVALHO et al. (1997), que utilizaram cinco novilhos zebuínos alimentados com feno de capimelefante (Pennisetum purpureum, Schum.) e concentrados nas proporções 80:20; 67,5:32,5; 55:45; 42,5:57,5; e 30:70, relataram degradabilidades efetivas médias calculadas para MS e PB, respectiva- mente, para o fubá de milho, de 62,5 e 57,9\% e para o farelo de soja, de 76,7 e 76,4\%.

O objetivo deste trabalho foi avaliar os efeitos de diferentes níveis de concentrado na dieta sobre as taxas de passagem e a cinética da degradação ruminal em bezerros holandeses.

\section{Material e Métodos}

O local, a época, as condições climáticas do experimento, os animais, as instalações e as dietas experimentais foram descritos por BÜRGER et al. (2000).

Cada período experimental teve duração de 29 dias, sendo as degradabilidades efetivas avaliadas do $19^{\circ}$ ao $22^{\circ}$ dia, a taxa de passagem de fluidos nos $22^{\circ}$ e $23^{\circ}$ dias e a taxa de passagem de partículas do $24^{\circ}$ ao $29^{\circ}$ dia.

A taxa de passagem de fluidos pelo rúmenretículo foi determinada utilizando-se Co-EDTA, conforme preconizado por UDÉN et al. (1980). O complexo Co-EDTA foi fornecido em dose única, de $5 \mathrm{~g}$ por animal, diluído em $400 \mathrm{~mL}$ de água destilada e infundido em vários pontos no rúmen, por intermédio da fístula. Foram coletadas amostras de $50 \mathrm{~mL}$ de fluido ruminal utilizando-se bomba de vácuo manual nos tempos 0 (pré-dosagem) e 2, 4, 6, 8, 12, 16, 24, 30 e 36 horas pós-dosagem, de acordo com COLUCCI et al. (1990). Para determinação da taxa de passagem de fluidos, as curvas de concentração ruminal do cobalto foram ajustadas ao modelo exponencial unicompartimental de Hungate (1966), citado por COLUCCI (1984):

$$
\mathrm{Y}_{\mathrm{Co}}=\mathrm{A} \cdot \mathrm{e}^{\left(-\mathrm{K}_{1} \cdot \mathrm{t}\right)}
$$

em que $\mathrm{Y}_{\mathrm{Co}}=$ concentração do indicador, no tempo t; $\mathrm{A}=$ concentração de equilíbrio do $\mathrm{Co}$; $\mathrm{K}_{1}=$ taxa de passagem ou de diluição do Co; e $\mathrm{t}=$ tempo de amostragem.

Para determinação da taxa de passagem de partículas no rúmen-retículo e no ceco-cólon proximal, procedeu-se ao ajuste das curvas de excreção fecal dos indicadores ao modelo exponencial bicompartimental, proposto por GROVUM e WILLIAMS (1973):$$
\mathrm{t} \geq \mathrm{TT}
$$$$
\mathrm{Y}_{\mathrm{Yb}, \mathrm{Cr}}=\mathrm{A} \cdot \mathrm{e}^{\left[-\mathrm{K}_{1}(\mathrm{t}-\mathrm{TT})\right]}-\mathrm{A} \cdot \mathrm{e}^{\left[-\mathrm{K}_{2}(\mathrm{t}-\mathrm{TT})\right]} \text { para }
$$

$$
\mathrm{Y}_{\mathrm{Yb}, \mathrm{Cr}}=0 \text { para } \mathrm{t}<\mathrm{TT} \text {, }
$$

em que $\mathrm{Y}_{\mathrm{Yb}}, \mathrm{Cr}=$ concentração do indicador nas fezes; $\mathrm{A}=$ parâmetro de escala; $\mathrm{K}_{1}=$ taxa de passagem de partículas no rúmen-retículo; $\mathrm{t}=$ tempo de amostragem, TT = tempo de trânsito ou estimativa do tempo em que o indicador apareceu pela primeira vez nas fezes; e $\mathrm{K}_{2}$ = taxa de passagem de partículas 
no ceco-cólon proximal.

A taxa de passagem de partículas do concentrado foi estimada com cloreto de itérbio $\left(\mathrm{YbCl}_{3}\right)$, fixado ao farelo de soja, utilizando-se a técnica proposta por Ellis e Beever (1984), citados por PEREIRA (1992), com algumas modificações.

A taxa de passagem do volumoso foi estimada com Cr-mordente ou Cr-FDN, fixado à parede celular do feno de capim coast-cross. Utilizou-se o método descrito por UDÉN et al. (1980) na preparação da fibra marcada.

As amostras marcadas do farelo de soja e do feno de capim coast-cross foram fornecidas aos animais 15 minutos antes da alimentação, via fístula ruminal, em doses únicas, respectivamente, 50 e $30 \mathrm{~g}$, acondicionadas em cápsulas de papel.

Coletaram-se, aproximadamente, $200 \mathrm{~g}$ de fezes nos intervalos de tempo de 12, 16, 24, 30, 36, 48, 72, 96 e 120 horas pós-dosagem (COLUCCI et al., 1990 e GOMES, 1991), acondicionadas em sacos plásticos identificados e imediatamente congelados a $-10^{\circ} \mathrm{C}$. No final de cada período, essas amostras foram descongeladas à temperatura ambiente e secas em estufa com circulação forçada de ar, a $60 \pm 5^{\circ} \mathrm{C}$, moídas em moinho tipo Willey, em peneira de $1 \mathrm{~mm}$, e armazenadas em frascos de vidro identificados, com tampa de polietileno.

As amostras de fezes, para determinação de itérbio, com o objetivo de estimar a curva de excreção do indicador do farelo de soja, foram preparadas segundo as recomendações de COLEMAN et al. (1984) e HUHTANEN e KUKKONEN (1995), por intermédio do método descrito por WILLIAMS et al. (1962), utilizando-se frascos de Erlenmeyer de $50 \mathrm{~mL}$, no processo de digestão ácida da matéria orgânica fecal, sendo analisadas em espectrofotômetro de absorção atômica, chama de óxido nitroso/acetileno, com comprimento de onda $\lambda=398,8 \mathrm{~nm}$ e fenda de 0,2 $\mathrm{mm}$. Os padrões do itérbio foram preparados nas concentrações de 4, 8, 12 e 15 ppm, diluídos em ácido clorídrico a $2 \%$. O método de WILLIAMS et al. (1962) foi igualmente utilizado nas determinações de cromo das fezes, para estimativa da curva de excreção do Cr-mordente do feno de capim coast-cross, usando-se espectrofotometria de absorção atômica, com chama de acetileno.

Os parâmetros do modelo unicompartimental de Hungate, em 1966, citado por COLUCCI (1984), e bicompartimental de GROVUM e WILLIAMS (1973) foram estimados por ajuste das curvas de concentração ruminal do cobalto e de excreção fecal do itérbio e cromo, utilizando-se o módulo de modelos nãolineares do programa Statistica for Windows, versão 5,0 A (STATSOFT, 1995).

Os parâmetros da dinâmica da fase líquida foram calculados conforme COLUCCI et al. (1990):

$$
\begin{gathered}
\text { TRRR }=1 / \mathrm{K}_{1 \mathrm{Co}} \\
\text { VLR }=\mathrm{Co} / \mathrm{A} \\
\text { FLR }=\mathrm{K}_{1 \mathrm{Co}} \text { VLR }
\end{gathered}
$$

em que TRRR (h) é tempo de retenção no rúmenretículo e $\mathrm{K}_{1 \mathrm{Co}}(\% / \mathrm{h})$, taxa de passagem de fluidos;

VLR (L) é volume de líquido de rúmen; Co (mg), a quantidade de cobalto fornecido; e A (mg/L), concentração de equilíbrio de cobalto; e

$\operatorname{FLR}(\mathrm{L} / \mathrm{h})$ é fluxo de líquido ruminal; $\mathrm{K}_{1 \mathrm{Co}}(\% / \mathrm{h})$, taxa de passagem de fluidos; e VLR (L), volume de líquido ruminal.

A taxa de reciclagem da fase líquida ruminal foi calculada conforme MAENG e BALDWIN (1976):

$$
\mathrm{REC}=24 \mathrm{~h} / \mathrm{TRRR}
$$

em que REC ( $\mathrm{n}$ o de vezes/dia) é taxa de reciclagem e TRRR (h), tempo de retenção no rúmen-retículo.

Os cálculos dos parâmetros da dinâmica fase sólida foram realizados de acordo com COLUCCI et al. (1990):

$$
\begin{aligned}
\mathrm{TRRR} & =1 / \mathrm{K}_{1} \\
\mathrm{TRCC} & =1 / \mathrm{K}_{2} \\
\mathrm{TMR} & =\mathrm{TRRR}+\mathrm{TRCC} \\
\mathrm{TRT} & =\mathrm{TMR}+\mathrm{TT}
\end{aligned}
$$

em que TRRR (h) é tempo de retenção no rúmenretículo; TRCC (h), tempo de retenção do ceco-cólon proximal; $\mathrm{K}_{1}(\% / \mathrm{h})$, taxa de passagem de partículas no rúmen-retículo; e $\mathrm{K}_{2}(\% / \mathrm{h})$, taxa de passagem de partículas no ceco-cólon proximal;

TMR (h) é tempo médio de retenção nos dois compartimentos; e

TRT (h) é tempo de retenção total e TT (h), tempo de trânsito.

Para determinação das degradabilidades potenciais da MS e PB do farelo de soja, fubá de milho e feno de capim coast-cross, foi adotada a técnica in situ, proposta por MEHREZ e ØRSKOV (1977), atendendo às recomendações descritas por NOCEK (1988), utilizando-se bolsas de tecido de náilon, com abertura de poro de $50 \mu \mathrm{m}$, nas dimensões de $6,5 \times 11,5 \mathrm{~cm}$, com costura dupla de linha do mesmo material e numeradas externamente. Foram colocadas, nas bolsas de náilon, amostras de 3,0 g de MS, em uma relação de aproximadamente $20 \mathrm{mg}$ de $\mathrm{MS} / \mathrm{cm}^{2} \mathrm{de}$ bolsa, do farelo de soja e fubá de milho, moídos em moinho com peneira de malha de $2 \mathrm{~mm}$, e do feno de capim coast-cross, moído em peneira com malha de 
$4 \mathrm{~mm}$. Os tempos de incubação utilizados foram 3, 6, 12, 24, 48 e 72 horas. As bolsas referentes ao tempo 0 , em duplicata, não foram incubadas no rúmen, mas imersas em recipiente com água destilada por 10 minutos. As bolsas após a incubação ruminal foram congeladas juntamente com as bolsas correspondentes ao tempo 0. Posteriormente, foram lavadas em água fria corrente até o clareamento da água e, após, secas em estufa com circulação forçada de ar, a $60 \pm 5^{\circ} \mathrm{C}$ por 48 horas, sendo pesadas a quente.

Para a descrição do comportamento cinético da digestão da MS e PB do farelo de soja, fubá de milho e feno de capim coast-cross, no rúmen, para cada nível de concentrado, utilizou-se o modelo exponencial de ØRSKOV e McDONALD (1979):

$$
\mathrm{DP}=\mathrm{a}+\mathrm{b}\left[1-\mathrm{e}^{(-\mathrm{c} \cdot \mathrm{t})}\right]
$$

em que DP é degradação potencial no tempo t; a, fração rapidamente solúvel em água; b, fração insolúvel em água, mas potencialmente degradável; c, taxa de degradação da fração b; e t, tempo de incubação em horas.

Os parâmetros do modelo de ØRSKOV e McDONALD (1979) foram estimados por ajuste das curvas de degradação, utilizando-se o módulo de modelos não-lineares do programa Statistica for Windows, versão 5,0 A (STATSOFT, 1995).

A degradabilidade potencial foi obtida por:

$$
\mathrm{DP}=\mathrm{a}+\mathrm{b}
$$

A fração potencialmente indegradada (i) foi determinada como:

$$
i=100-(a+b)
$$

A degradabilidade efetiva ou teórica de MS e PB do farelo de soja, fubá de milho e feno de capim coast-cross, para cada nível de concentrado, foi calculada pela equação:

$$
\mathrm{DE}=\mathrm{a}+[(\mathrm{b} \times \mathrm{c}) /(\mathrm{c}+\mathrm{k})]
$$

em que DE é degradabilidade efetiva e $k$, taxa de passagem de partículas no rúmen.

As degradabilidades efetivas da MS e PB do farelo de soja, fubá de milho e feno de capim coastcross foram calculadas utilizando-se os valores individuais das taxas de passagem de partículas no rúmen-retículo, obtidas com o cloreto de itérbio, para o farelo de soja, e $\mathrm{Cr}$-mordente para o feno de capim coast-cross, assumindo-se similares as taxas de passagem do farelo de soja e do fubá de milho.

O experimento foi realizado utilizando-se delineamento experimental em quadrado latino 5 x 5 (cinco animais cinco períodos) e cinco tratamentos, correspondentes aos níveis de 30, 45, 60, 75 e $90 \%$ de concentrado. Os dados experimentais foram analisa- dos empregando-se o programa SAEG-Sistema de Análises Estatísticas e Genéticas, versão 7.1 (UNIVERSIDADE..., 1997). Os resultados foram interpretados estatisticamente por meio de análises de variância e regressão, adotando-se nível de 5\% de probabilidade. Os modelos foram selecionados com base no coeficiente de determinação e na significância dos coeficientes de regressão, adotando-se nível de $5 \%$ de probabilidade, utilizando-se o teste $\mathrm{F}$.

\section{Resultados e Discussão}

Os resultados relativos à estimativa da taxa de passagem de fluidos, do tempo de retenção no rúmen, da taxa de reciclagem da fase líquida ruminal, do volume de líquido de rúmen e do fluxo de líquido ruminal, às respectivas equações de regressão ajustadas e aos coeficientes de determinação são apresentados na Tabela 1. As estimativas dos valores das taxas de passagem e dos tempos médios de retenção no rúmen-retículo e da taxa de reciclagem da fase líquida ruminal apresentaram comportamento quadrático, com estimativas dos valores, máximo de 9,73\%/h, mínimo de 11,14 horas e máximo de 2,33 vezes/dia, para os níveis de 61,99; 59,46 e 61,99\% de concentrado nas dietas, respectivamente. $\mathrm{O}$ valor máximo estimado para a passagem de fluidos de $9,73 \%$ /h foi próximo às médias de 10,18 e 10,1\%/h apresentadas por FIRKINS et al. (1986) e CAREY et al. (1993) e ligeiramente abaixo dos valores de 11,7 e $10,85 \% / \mathrm{h}$ relatados por GUNTER et al. (1990) e PEYRAUD et al. (1997).

Em experimento que testou o fornecimento de feno de capim coast-cross suplementado com fubá de milho, para novilhas mestiças de corte, com peso vivo médio de $396 \mathrm{~kg}$, JONES et al. (1988) obtiveram taxa de passagem de fluidos média de $6,8 \% / \mathrm{h}$, próxima do valor de $6,97 \% / \mathrm{h}$, apresentado na Tabela 1 , referido para o nível de $30 \%$ de concentrado. Entretanto, os resultados obtidos neste trabalho para a taxa de passagem de fluidos não apresentaram comportamento semelhante àquele referido por EVANS (1981) e GOETSCH e GALYEAN (1982), os quais relataram que a taxa de passagem de fluidos foi maior em dietas com alta proporção de forragem. OSPINA (1995) mencionou que, em geral, animais alimentados com volumosos apresentam maiores taxas de passagem da fase líquida que animais alimentados com concentrados, estando este fato aparentemente relacionado à maior produção salivar.

OWENS e GOETSCH (1986) relataram taxas de 
passagem de fluidos de $8,2 \% / \mathrm{h}$ entre 0 e $50 \%$ de concentrado; $6,7 \% / \mathrm{h}$ entre 50 e $80 \%$; e $5,2 \% / \mathrm{h}$ acima de $80 \%$. Pelos resultados contidos na Tabela 1, podese observar que, a partir do nível de $61,99 \%$ de concentrado, ocorreu redução nas taxas de passagem, apesar de os valores terem sido superiores aos relatados por esses autores. A variação nos resultados obtidos e citados poderia estar relacionada ao tipo de indicador e grau de moagem do alimento, que influencia a produção de saliva, e ao nível de ingestão.

Ovalor máximo estimado para a taxa de reciclagem da fase líquida ruminal de 2,33 no de vezes/dia, para o nível de $61,99 \%$ de concentrado, foi similar aos valores de 2,41 e 2,38, relatados por FIRKINS et al. (1986) e CAREY et al. (1993), e próximo da média de 2,0 referida por BERCHIELLI (1994).

Observou-se efeito linear decrescente $(\mathrm{P}<0,05)$ para as estimativas do volume de fluido ruminal (Tabela 1), em litros, L/kgPV e $\mathrm{L} / \mathrm{kg}^{0,75}$. Na metodologia utilizada, o Co-EDTA superestimou o volume de líquido ruminal, que foi, em média, 93,14 litros, correspondendo a $56,73 \%$ do peso corporal médio de 164,2 $\mathrm{kg}$ dos bezerros, superior aos 15 a $21 \%$ relatados por OWENS e GOETSCH (1986) e 20,53\% citados por BERCHIELLI (1994) para o volume ruminal de bovinos.

Segundo COLUCCI (1984), têm sido relatados problemas com a estimativa do volume de líquido ruminal nos trabalhos em que se utilizaram altos níveis de concentrado na dieta, levando a alterações na viscosidade do conteúdo ruminal e, conseqüentemente, na mistura instantânea do indicador, podendo fazer com que a concentração desse indicador nos primeiros tempos de coleta seja menor que nos tempos finais. Também de acordo com COLUCCI et al. (1990), a taxa de diluição aumentou com o nível de ingestão e o volume de líquido ruminal foi reduzido com o aumento na proporção de concentrado da dieta.

Houve efeito quadrático para o valor do fluxo de líquido ruminal, com estimativa do valor máximo de $8,58 \mathrm{~L} / \mathrm{h}$, correspondendo ao nível de $52,28 \%$ de concentrado na dieta.

As estimativas das taxas de passagem de partículas do farelo de soja e do feno de capim coast-cross, no rúmen-retículo e no ceco-cólon proximal, do tempo de trânsito, tempo de retenção no rúmen-retículo, tempo de retenção no ceco-cólon proximal, tempo médio de retenção nos dois compartimentos e tempo de retenção total, as equações de regressão ajustadas e os coeficientes de regressão constam da Tabela 2.

A taxa de passagem de partículas do farelo de soja no rúmen-retículo apresentou comportamento linear decrescente $(\mathrm{P}<0,01)$, ao passo que no cecocólon proximal não foi influenciada pelo aumento do nível de concentrado das dietas, sendo observado valor médio de $7,30 \% / \mathrm{h}$. CECAVA e PARKER (1993), trabalhando com novilhos holandeses com peso vivo médio de $320,0 \pm 7,8 \mathrm{~kg}$ e 10 meses de idade, alimentados com silagem de milho e concentrado à base de farelo de soja e farelo de glúten de milho, na proporção 62:38, encontraram taxa de passagem de partículas do concentrado marcado com itérbio de $6,86 \% / \mathrm{h}$ intermediária à amplitude de 7,85 e $6,67 \% / \mathrm{h}$ da taxa de passagem ruminal e da média do ceco-

Tabela 1 - Médias da taxa de passagem de fluidos $\left(\mathrm{K}^{1 \mathrm{Co}}\right)$, do tempo de retenção no rúmen-retículo (TRRR), da taxa de reciclagem (REC), do volume de líquido de rúmen (VLR) e do fluxo de líquido ruminal (FLR), em função dos níveis de concentrado das dietas experimentais

Table 1 - Means of the fluid passage rate $\left(K^{1 C 0}\right)$, rumen-reticulum retention time (TRRR), turnover rate (REC), rumen fluid volume (VLR), ruminal fluid flow (FLR), in function of the concentrate levels in the experimental diet

\begin{tabular}{|c|c|c|c|c|c|c|}
\hline \multirow[t]{2}{*}{ Item } & \multicolumn{5}{|c|}{$\begin{array}{c}\text { Nível de concentrado }(\%) \\
\text { Concentrate level }\end{array}$} & \multirow[t]{2}{*}{$\begin{array}{l}\text { Regressão } \\
\text { Regression }\end{array}$} \\
\hline & 30 & 45 & 60 & 75 & 90 & \\
\hline $\mathrm{K}^{1 \mathrm{Co}}(\% / \mathrm{h})$ & 6,97 & 8,15 & 10,21 & 9,28 & 7,29 & 1 \\
\hline TRRR (h) & 15,05 & 13,26 & 10,26 & 12,42 & 15,87 & 2 \\
\hline REC (vezes/dia) & 1,67 & 1,96 & 2,45 & 2,23 & 1,75 & 3 \\
\hline VLR(L) & 109,40 & 99,00 & 96,91 & 80,34 & 80,07 & 4 \\
\hline $\mathrm{VLR}_{\mathrm{PV}}(\mathrm{L} / \mathrm{kgPV})$ & 0,69 & 0,58 & 0,59 & 0,53 & 0,49 & 5 \\
\hline $\operatorname{FLR}(\mathrm{L} / \mathrm{h})$ & 7,53 & 7,78 & 9,47 & 6,62 & 5,27 & 6 \\
\hline
\end{tabular}

1. $\hat{Y}=-0,01664+0,003675^{n s} C-0,00002964^{*} C^{2}, R^{2}=0,88 ; \quad 2 . \quad \hat{Y}=28,6859-0,5901^{n s} C+0,004962^{* *} C^{2}$, $R^{2}=0,89 ; 3 . \hat{Y}=-0,3993+0,08819^{n s} C-0,0007113^{*} C^{2}, R^{2}=0,88 ; 4 . \hat{Y}=124,083-0,5156^{*} C, r^{2}=0,92 ; 5$. $\hat{\mathrm{Y}}=0,7623-0,003081^{*} C, r^{2}=0,89 ; 6 . \hat{Y}=1,8649+0,25711^{* *} C-0,002459^{* *} C^{2}, R^{2}=0,78 ;{ }^{*} e^{* *}(P<0,10)$ e $(P<0,05)$, pelo teste $F$ (by $F$ test); ${ }^{\text {ns }}(P>0,10)$ pelo teste $F$ (by $F$ test); e $C=$ Nível de concentrado nas dietas experimentais (Concentrate level in the experimental diets). 
cólon proximal de 7,30\%/h observadas na Tabela 2. LOPEZ-GUISA e SATTER (1991), em um experimento com novilhas holandesas, com peso médio de $414 \mathrm{~kg}$, alimentadas com feno de alfafa e resteva de milho, mais farelo de glúten de milho e resíduo de cervejaria, marcados ambos com lantânio e itérbio, verificaram que as taxas de passagem no ceco-cólon proximal, para o lantânio, foram, respectivamente, 7,8 e 7,4\%/h, próximas ao valor encontrado para o farelo de soja, 7,30\%/h. Os mesmos autores relataram o valor de 49,2 horas para o tempo médio de retenção total do farelo de glúten de milho, acima da média de 39,60 horas, apresentada para o farelo de soja marcado com itérbio (Tabela 2). Para o feno de capim coast-cross, as taxas de passagem no rúmen-retículo e no ceco-cólon proximal não foram influenciadas pelo aumento do nível de concentrado nas dietas, apresentando valores médios de 3,97 e 4,32\%/h, respectivamente. Trabalhando com bezerros holan- deses desaleitados progressivamente com 7 a 10 semanas de idade e alimentados com feno e $80 \%$ de concentrados, predominando farelo de soja, LALLES e PONCET (1990) obtiveram, às 19-20 semanas de idade, taxa de passagem do feno no rúmen-retículo de $3,6 \% / \mathrm{h}$. Esse resultado foi semelhante ao valor de $3,66 \% / \mathrm{h}$, relatado para o nível de $75 \%$, para o feno de capim coast-cross (Tabela 2).

GALLOWAY et al. (1993) obtiveram o valor de $4,18 \% / \mathrm{h}$ em bezerros holandeses com peso vivo inicial de $210 \pm 9,2 \mathrm{~kg}$, alimentados com feno de capim coast-cross suplementado com concentrado à base de fubá de milho e casca de soja, para a estimativa da taxa de passagem de partículas, do feno marcado com itérbio. Esse valor é intermediário aos valores de 3,97 e 4,32\%/h (Tabela 2) obtidos, respectivamente, para as taxas de passagem no rúmen-retículo e no ceco-cólon proximal.

O tempo de trânsito (Tabela 2) das partículas do

Tabela 2 - Médias da taxa de passagem de partículas do farelo de soja e do feno de capim coastcross, no rúmen-retículo $\left(\mathrm{K}_{1}\right)$, e no ceco-cólon proximal $\left(\mathrm{K}_{2}\right)$, tempo de trânsito (TT), tempo de retenção no rúmen-retículo (TRRR), tempo de retenção no ceco-cólon proximal (TRCC), tempo médio de retenção nos dois compartimentos (TMR) e tempo de retenção total (TRT), em função dos níveis de concentrado das dietas experimentais

Table 2 - Means of the particles passage rate of soybean meal and of the coast cross grass hay, at the rumenreticulum $\left(K_{1}\right)$, and at the proximal cecum-colum $\left(K_{2}\right)$, transit time $(T T)$, retention time at the rumenreticulum (TRRR), retention time at the proximal cecum-colum, mean retention time at the two compartiments (TMR) and total retention time (TRT), in function of the the concentrate levels in the experimental diet

\begin{tabular}{|c|c|c|c|c|c|c|}
\hline \multirow[t]{2}{*}{ Item } & \multicolumn{5}{|c|}{$\begin{array}{l}\text { Nível de concentrado (\%) } \\
\text { Concentrate level }\end{array}$} & \multirow[t]{2}{*}{$\begin{array}{l}\text { Regressão } \\
\text { Regression }\end{array}$} \\
\hline & 30 & 45 & 60 & 75 & 90 & \\
\hline \multicolumn{7}{|c|}{ Farelo de soja (S) } \\
\hline & \multicolumn{5}{|c|}{ Soybean meal } & \\
\hline $\mathrm{K}_{1 \mathrm{~S}}(\% / \mathrm{h})$ & 7,85 & 7,58 & 6,79 & 6,88 & 6,67 & 1 \\
\hline $\mathrm{K}_{2 \mathrm{~S}}(\% / \mathrm{h})$ & 7,99 & 7,69 & 6,89 & 7,03 & 6,92 & $\hat{\mathrm{Y}}=7,30$ \\
\hline $\mathrm{TT}_{\mathrm{S}}(\mathrm{h})$ & 13,19 & 12,83 & 10,16 & 9,31 & 9,94 & 2 \\
\hline $\operatorname{TRRR}_{\mathrm{S}}(\mathrm{h})$ & 13,36 & 13,35 & 15,38 & 14,69 & 15,31 & 3 \\
\hline $\mathrm{TRCC}_{\mathrm{S}}(\mathrm{h})$ & 13,05 & 13,14 & 15,15 & 14,40 & 14,73 & $\hat{Y}=14,09$ \\
\hline $\mathrm{TMR}_{\mathrm{S}}(\mathrm{h})$ & 26,41 & 26,50 & 30,53 & 29,09 & 30,04 & $\hat{\mathrm{Y}}=28,51$ \\
\hline \multirow{3}{*}{$\mathrm{TRT}_{\mathrm{S}}(\mathrm{h})$} & 39,60 & 39,33 & 40,69 & 38,40 & 39,98 & $\hat{\mathrm{Y}}=39,60$ \\
\hline & \multirow{2}{*}{\multicolumn{5}{|c|}{$\begin{array}{c}\text { Feno de capim coast-cross }(\mathrm{F}) \\
\text { Coast cross grass hay }\end{array}$}} & \\
\hline & & & & & & \\
\hline $\mathrm{K}_{1 \mathrm{~F}}(\% / \mathrm{h})$ & 4,11 & 4,04 & 4,12 & 3,66 & 3,91 & $\hat{\mathrm{Y}}=3,97$ \\
\hline $\mathrm{K}_{2 \mathrm{~F}}(\% / \mathrm{h})$ & 4,43 & 4,46 & 4,42 & 4,09 & 4,20 & $\hat{Y}=4,32$ \\
\hline $\mathrm{TT}_{\mathrm{F}}(\mathrm{h})$ & 13,56 & 12,97 & 13,05 & 12,71 & 13,10 & $\hat{\mathrm{Y}}=13,08$ \\
\hline $\operatorname{TRRR}_{\mathrm{F}}(\mathrm{h})$ & 24,55 & 24,97 & 25,18 & 27,73 & 25,73 & $\hat{Y}=25,63$ \\
\hline $\operatorname{TRCC}_{\mathrm{F}}(\mathrm{h})$ & 22,88 & 22,82 & 23,38 & 25,15 & 23,92 & $\hat{\mathrm{Y}}=23,63$ \\
\hline $\mathrm{TMR}_{\mathrm{F}}(\mathrm{h})$ & 47,42 & 47,79 & 48,56 & 52,89 & 49,65 & $\hat{\mathrm{Y}}=49,26$ \\
\hline $\operatorname{TRT}_{\mathrm{F}}(\mathrm{h})$ & 60,98 & 60,76 & 61,62 & 65,60 & 62,76 & $\hat{Y}=62,34$ \\
\hline
\end{tabular}

I. $\hat{Y}=0,08378-0,0002037^{\star} \mathrm{C}, \mathrm{r}^{2}=0,85 ; 2$. $\hat{\mathrm{Y}}=15,0951-0,06683^{*} \mathrm{C}, \mathrm{r}^{2}=0,78 ; 3 . \hat{\mathrm{Y}}=12,3241+0,03491^{*} \mathrm{C}$, $r^{2}=0,68 ;{ }^{* *}(P<0,01)$ pelo teste $F$ (by the $F$ test $)$; e $C=$ Nível de concentrado nas dietas experimentais (Concentrate level in the experimental diets). 
farelo de soja decresceu linearmente $(\mathrm{P}<0,05)$, ao passo que o do feno de capim coast-cross não foi influenciado, em função dos níveis crescentes de concentrado, observando-se valor médio de 13,08 horas. Este valor foi semelhante ao tempo de trânsito de 13 horas, obtido por LALLES e PONCET (1990), com bezerros holandeses, com 15-16 semanas de idade, alimentados com feno e concentrado. Em outro estudo, LALLES et al. (1991) alimentaram bezerros holandeses com concentrado à base de farelo de soja, registrando tempo médio de trânsito de 12,86 horas similar ao valor de 12,83 horas relativo, no nível de $45 \%$ de concentrado (Tabela 2).

Observou-se para o tempo de retenção do farelo de soja, no rúmen-retículo (Tabela 2), efeito linear positivo; contudo, no ceco-cólon proximal, o tempo médio de retenção e o tempo de retenção total não foram influenciados pelos níveis de concentrado, apresentando valores médios de 14,09; 28,51; e 39,60 horas. MOLONEY et al. (1994) realizaram experimento com novilhos holandeses alimentados com feno de cevada e níveis crescentes de concentrado à base de farelo de soja peletizado, relatando tempo médio de retenção de 27,2 horas, similar ao valor 28,51 horas registrado na Tabela 2 .

LALLES et al. (1991), que utilizaram bezerros holandeses desmamados, com 9 a 20 semanas de idade, verificaram o tempo de retenção total de 39,7 horas para o concentrado à base de farelo de soja, valor similar a 39,6 horas relatado na Tabela 2. O tempo de retenção do concentrado no rúmen-retículo, de 21,13 horas, foi superior e o tempo de retenção no ceco-cólon proximal, de 5,67 horas, inferior aos valores apresentados na Tabela 2.

O tempo de retenção do feno de capim coastcross, no rúmen-retículo e ceco-cólon proximal, o tempo médio de retenção e o tempo de retenção total não foram influenciados pelos níveis crescentes de concentrado, apresentando valores médios de 25,63; 23,63; 49,26; e 62,34, respectivamente. Em outros estudos, LALLES e PONCET (1990) e HESS et al. (1996) relataram para volumosos tempos médios de retenção de 47,8 e 48,3 horas, respectivamente.

As estimativas da fração solúvel inicial(a), fração insolúvel potencialmente degradável(b), taxa de degradação(c) e respectivas equações ajustadas para a degradação potencial (DP); fração insolúvel indigerível e degradação efetiva (DE), da cinética da degradação ruminal in situ de matéria seca (MS), farelo de soja, fubá de milho e feno de capim coastcross são apresentadas na Tabela 3 .
A fração $a$, a taxa de degradação $c$ e a DE da MS do farelo de soja não foram influenciadas pelos níveis de concentrado, observando-se valores médios de $28,83 \%$; $7,34 \% / \mathrm{h}$; e $63,54 \%$. A fração $b$ e a DP apresentaram comportamento linear decrescente $(\mathrm{P}<0,05$ e $\mathrm{P}<0,01$, respectivamente) e a fração $i$, linear crescente $(\mathrm{P}<0,01)$. O valor médio do coeficiente $a$, para a MS do farelo de soja de $28,83 \%$, foi próximo ao valor de $26,8 \%$ relatado por DESCHAMPS (1994), que trabalhou com novilhos Holandês-Jersey alimentados com capim-elefante (Pennisetum purpureum, Schum) e suplementados com concentrado com $18 \%$ PB.

A taxa média de degradação $c$ da MS do farelo de soja de 7,34\%/h foi similar ao valor de 7,56\%/h encontrado por MIRON et al. (1996) e de 8,12 e $8,00 \% / \mathrm{h}$, respectivamente, para os níveis de 30 e $45 \%$ de concentrado, valores também semelhantes ao de $8,1 \% / \mathrm{h}$ relatado por CARVALHO et al. (1997), para o nível de $45 \%$ de concentrado, fornecido a novilhos zebuínos.

As degradabilidades potencial e efetiva da MS do farelo de soja relatadas por AROEIRA et al. (1996), foram, respectivamente, similar, 99,1\% (níveis de 30, 45 e $60 \%$ de concentrado), e superior, $75,9 \%$, ao valor médio apresentado na Tabela 3. O valor médio de $63,54 \%$ observado para a DE da MS do farelo de soja foi intermediário aos valores de 68,3 e 59,4\% relatados por VILELA (1994), para as taxas de passagem de 5 e $8 \% / \mathrm{h}$, respectivamente. Para MS do fubá de milho, não houve variação da fração $a$, que apresentou valor médio de 13,69\%; no entanto, a fração $b$ e a DP apresentaram comportamento quadrático, com estimativas dos valores máximos de $b$ e da DP, de 86,34 e 99,94\%, correspondendo aos níveis de 36,25 e 35,83\% de concentrado nas dietas, respectivamente. Efeito quadrático foi igualmente registrado para a fração $i$, com estimativa do valor mínimo de $0,06 \%$, relativo ao nível de inclusão de $35,83 \%$ de concentrado. A taxa de degradação $c$ e a DE sofreram efeito linear positivo $(\mathrm{P}<0,01)$ dos níveis crescentes de concentrado.

Para a MS do fubá de milho, o valor médio observado para a fração a, de $13,89 \%$, foi similar ao valor $13,79 \%$ apresentado por VALADARES FILHO et al. (1990).

O teor de MS do fubá de milho apresentou taxa de degradação média de $5,18 \%$ /h para o nível de $30 \%$ de concentrado, semelhante ao valor de $5,1 \% / \mathrm{h}$ observado por CARVALHO et al.(1997), que trabalharam com novilhos zebuínos recebendo dieta com $45 \%$ de concentrado.

A degradabilidade potencial da MS do fubá de milho, nas rações com 30, 45 e 60\% de concentrado, 
Tabela 3 - Estimativas da fração solúvel inicial (a), fração insolúvel potencialmente degradável (b), taxa de degradação (c), degradação potencial (DP); fração indegradável (i),e da degradação efetiva (DE), da Matéria Seca (MS) do farelo de soja, fubá de milho e feno de capim coastcross, em função dos níveis de concentrado das dietas experimentais

Table 3 - Estimates of the initial soluble fraction (a), potential insoluble fraction (b), rate of degradation (c), potential degradation (PD), indegradable fraction (i), and effective degradation (ED), of dry matter (DM) of soybean meal, corn ground grain and coast cross grass hay in function of the concentrate level in the experimental diet

\begin{tabular}{|c|c|c|c|c|c|c|c|}
\hline \multirow[t]{2}{*}{$\begin{array}{l}\text { Substrato } \\
\text { Substrate }\end{array}$} & \multirow[t]{2}{*}{ Item $(\%)$} & \multicolumn{5}{|c|}{$\begin{array}{c}\text { Nível de concentrado (\%) } \\
\text { Concentrate level }\end{array}$} & \multirow[t]{2}{*}{$\begin{array}{c}\text { Regressão } \\
\text { Regression }\end{array}$} \\
\hline & & 30 & 45 & 60 & 75 & 90 & \\
\hline \multirow{3}{*}{$\begin{array}{l}\text { MS Farelo de soja } \\
\text { DM Soybean } \\
\text { meal }\end{array}$} & $\begin{array}{l}\mathrm{a} \\
\mathrm{b}\end{array}$ & $\begin{array}{l}28,46 \\
71,92\end{array}$ & $\begin{array}{l}28,86 \\
70,80\end{array}$ & $\begin{array}{l}29,21 \\
71,49\end{array}$ & $\begin{array}{l}28,55 \\
68,46\end{array}$ & $\begin{array}{l}29,06 \\
66,25\end{array}$ & $\begin{array}{c}\hat{\mathrm{Y}}=28,83 \\
1\end{array}$ \\
\hline & $\begin{array}{c}\mathrm{c}^{14} \\
\mathrm{i}^{15} \\
\mathrm{DP}(P D)\end{array}$ & $\begin{array}{r}8,12 \\
-0,38 \\
100,38\end{array}$ & $\begin{array}{r}8,00 \\
0,33 \\
99,66\end{array}$ & $\begin{array}{r}6,33 \\
-0,70 \\
100,70\end{array}$ & $\begin{array}{r}7,66 \\
2,99 \\
97,01\end{array}$ & $\begin{array}{r}6,61 \\
4,68 \\
95,31\end{array}$ & $\begin{array}{c}\hat{\mathrm{Y}}=7,34 \\
2 \\
3\end{array}$ \\
\hline & $\mathrm{DE}(E D)$ & 64,62 & 66,30 & 63,25 & 62,98 & 60,56 & $\hat{\mathrm{Y}}=63,54$ \\
\hline \multirow{5}{*}{$\begin{array}{l}\text { MS Fubá de milho } \\
\text { DM corn } \\
\text { ground grain }\end{array}$} & $\begin{array}{l}\mathrm{a} \\
\mathrm{b}\end{array}$ & $\begin{array}{l}13,53 \\
85,94\end{array}$ & $\begin{array}{l}13,89 \\
86,31\end{array}$ & $\begin{array}{l}13,20 \\
86,21\end{array}$ & $\begin{array}{l}13,99 \\
80,54\end{array}$ & $\begin{array}{l}13,83 \\
79,62\end{array}$ & $\hat{\mathrm{Y}}=\begin{array}{c}13,69 \\
4 \\
5\end{array}$ \\
\hline & $c^{14}$ & 5,18 & 5,76 & 6,60 & 8,38 & 9,40 & 5 \\
\hline & $i^{15}$ & 0,52 & $-0,20$ & 0,59 & 5,47 & 6,55 & 6 \\
\hline & $\mathrm{DP}(P D)$ & 99,47 & 100,20 & 99,41 & 94,52 & 93,45 & 7 \\
\hline & $\mathrm{DE}(E D)$ & 47,20 & 51,61 & 54,06 & 56,20 & 58 & 8 \\
\hline \multirow{2}{*}{$\begin{array}{l}\text { MS feno de capim } \\
\text { coast-cross }\end{array}$} & $\mathrm{a}$ & 11,69 & 11,88 & 12,30 & 12,81 & 12,92 & 9 \\
\hline & b & 47,00 & 48,47 & 38,44 & 12,74 & 9, & 10 \\
\hline \multirow{4}{*}{$\begin{array}{l}\text { DM Coast } \\
\text { cross grass } \\
\text { hay }\end{array}$} & $\mathrm{c}$ & 3,4 & 2,77 & 2,57 & 3,61 & 2 , & \multirow{4}{*}{$\begin{array}{c}\hat{\mathrm{Y}}=3,08 \\
11 \\
12 \\
13\end{array}$} \\
\hline & $\mathrm{i}$ & 41,31 & 39,64 & 49,26 & 74,44 & & \\
\hline & $\mathrm{DP}(P D)$ & 58,69 & 60,35 & 50,74 & 25,55 & 22,25 & \\
\hline & $\mathrm{DE}(E D)$ & 33,85 & 32,22 & 26,91 & 18,57 & 16,98 & \\
\hline \multicolumn{8}{|c|}{ 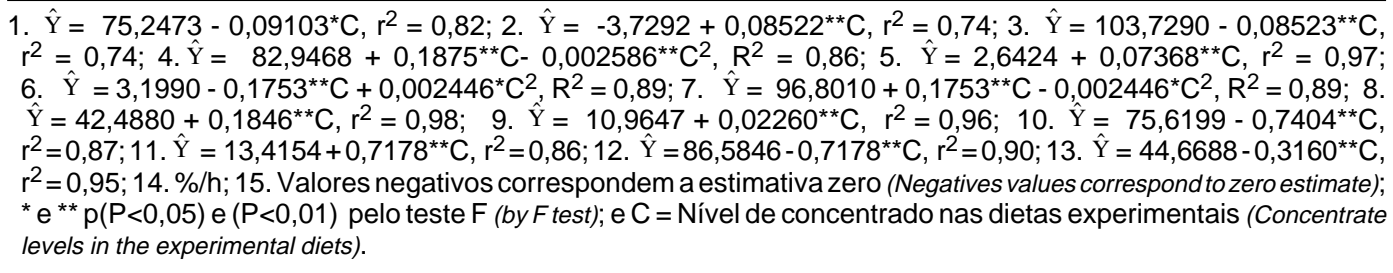 } \\
\hline
\end{tabular}

foram de 99,47; 100,20; e 99,41\% (Tabela 3), similares ao valor de $99,50 \%$ relatado por CHATURVEDI e WALLI (1995), que trabalharam com bezerros mestiços com peso vivo médio de $253,0 \pm 25,0 \mathrm{~kg}$, alimentados com palha de trigo e concentrado, na proporção 65:35.

Os valores da degradabilidade ruminal da MS apresentados pelo NATIONAL RESEARCH COUNCIL - NRC (1996) para o farelo de soja e fubá de milho, respectivamente, 66 e $45 \%$, encontram-se relativamente próximos às médias apresentadas na Tabela 3,63,54\% e 47,20 a 58,75\%, relativos aos níveis de 30 a $90 \%$ de concentrado.

As estimativas dos coeficientes $a$ e $i$ da MS do feno de capim coast-cross apresentaram efeito linear crescente $(\mathrm{P}<0,01)$, em função dos níveis de concentrado; ocorreu comportamento linear decrescente $(\mathrm{P}<0,01)$ para a fração $b, a \mathrm{DP}$ e a DE, sendo que a taxa de degradação $c$ não foi influenciada pelos níveis de concentrado.
Na Tabela 4, são apresentadas as estimativas dos coeficientes $a$, fração solúvel inicial; $b$, fração insolúvel potencialmente degradável; e $c$, taxa de degradação da fração $b$; das equações ajustadas para a DP; $i$, fração insolúvel indigerível; e a DE da cinética degradação ruminal in situ da proteína bruta $(\mathrm{PB})$ do farelo de soja, fubá de milho e feno de capim coastcross, as equações de regressão ajustadas e os coeficientes de determinação.

As estimativas dos coeficientes $a, b$ e $i$, a DP e DE e a taxa de degradação $c$ da PB do farelo de soja não foram influenciadas pelos níveis de concentrado, apresentando valores médios de 7,60; 93,12; -0,72; 100,$72 ; 56,81 \%$; e $8,16 \% / \mathrm{h}$.

Para o farelo de soja, o coeficiente $a$ foi inferior à estimativa de $14 \%$ e o $b$, superior aos valores de $86 \%$, citados por BRODERICK (1995). A degradabilidade efetiva da PB do farelo de soja de $56,81 \%$ foi similar ao resultado de $56 \%$ relatado por 
Alderman et al. (1992), citados por ANDRADE (1994), e intermediário aos valores de 63 e 50\%, para as taxas de passagem de 5 e $8 \% / \mathrm{h}$ referidos pelo AGRICULTURAL RESEARCH COUNCIL - ARC (1984).

Os valores médios dos coeficientes $a$ e $b$ (Tabela 4 ), relativos ao desaparecimento da PB do farelo de soja, $7,60 \mathrm{e} 93,12 \%$, foram, respectivamente, inferiores e superiores, aos relatados por VILELA (1994), 17,4 e 80,0\%.

A estimativa média da taxa de degradação $c$ do farelo de soja, de $8,16 \% / \mathrm{h}$, foi semelhante ao valor de $8,1 \% / \mathrm{h}$ relatado por AROEIRA et al. (1996) e relativamente próxima da média de $9,1 \% / \mathrm{h}$, obtida por LARDY et al.(1993).

O valor estimado médio para a DE da PB do farelo de soja, de $56,81 \%$, foi próximo de $58,62 \%$, relatado por MASOERO et al. (1994) e intermédio aos valores citados pelo NRC $(1985,1989)$ de 41 a $65 \%$.

Para a PB do fubá de milho, não houve variação nas estimativas das frações $a, b$ e $i$, da taxa de degradação $c$ e da DP, sendo registrados os respectivos valores médios de 17,$66 ; 83,15 ;-0,81 ; 4,95 \% / \mathrm{h}$; e $100,81 \%$; no entanto, a DE apresentou efeito linear crescente $(\mathrm{P}<0,05)$ em função dos níveis de concentrado das dietas.

O valor médio estimado para a DE da PB do fubá de milho para a taxa de passagem de $6 \% / \mathrm{h}$, citado por MICHALET-DOREAU et al. (1997), de 52,0\%, foi próximo às médias observadas neste trabalho. Igualmente, as estimativas da DE da PB desse mesmo substrato, de 48,10 a $55,13 \%$, foram similares aos valores da degradabilidade ruminal, apresentados pelo NRC (1985, 1989), de 40 a 57\% (Tabela 4).

As estimativas da fração $a$ e da DE da PB do feno de capim coast-cross não foram influenciadas pelos níveis de concentrado, apresentando valores médios respectivos de 14,19 e $30,76 \%$. Contudo, a fração $b$ e a DP apresentaram comportamento linear decrescente $(\mathrm{P}<0,05)$ e a fração $i$ e a taxa de degradação $c$, efeito linear crescente $(\mathrm{P}<0,05)$.

$\mathrm{O}$ valor da taxa de degradação c, da PB do feno de capim coast-cross, referida por AROEIRA et al. (1996), de 3,4\%/h, foi próximo aos valores de 3,35 e $3,41 \% / \mathrm{h}$ observados para os níveis de 30 e $45 \%$ de concentrado (Tabela 4).

Tabela 4 - Estimativas da fração solúvel inicial (a), fração insolúvel potencialmente degradável (b), taxa de degradação (c), degradação potencial (DP), fração indegradável (i) e degradação efetiva (DE) da proteína bruta (PB) do farelo de soja, fubá de milho e feno de capim coastcross, em função dos níveis de concentrado das dietas experimentais

Table 4 - Estimates of the initial soluble fraction (a), potential insoluble fraction (b), rate of degradation (c), potential degradation $(P D)$, indegradable fraction (i), and effective degradation (ED), of crude protein $(C P)$ soybean meal, corn ground grain and coast cross grass, in function of the concentrate levels in the experimental diet

\begin{tabular}{|c|c|c|c|c|c|c|c|}
\hline \multirow[t]{2}{*}{$\begin{array}{l}\text { Substrato } \\
\text { Substrate }\end{array}$} & \multirow[t]{2}{*}{$\operatorname{Item}(\%)$} & \multicolumn{5}{|c|}{$\begin{array}{c}\text { Nível de concentrado }(\%) \\
\text { Concentrate level }\end{array}$} & \multirow[t]{2}{*}{$\begin{array}{l}\text { Regressão } \\
\text { Regression }\end{array}$} \\
\hline & & 30 & 45 & 60 & 75 & 90 & \\
\hline & $\mathrm{a}$ & 7,67 & 8,30 & 7,35 & 7,98 & 6,72 & $\hat{\mathrm{Y}}=7,60$ \\
\hline & b & 93,66 & 92,69 & 93,10 & 91,82 & 94,33 & $\hat{Y}=93,12$ \\
\hline PB Farelo de soja & $c^{6}$ & 8,91 & 8,33 & 8,18 & 8,51 & 6,88 & $\hat{\mathrm{Y}}=8,16$ \\
\hline CP Soybean & $\mathrm{i}^{7}$ & $-1,33$ & $-0,99$ & $-0,45$ & 0,20 & $-1,05$ & $\hat{\mathrm{Y}}=-0,72$ \\
\hline \multirow[t]{4}{*}{ meal } & $\mathrm{DP}(P D)$ & 101,33 & 100,99 & 100,45 & 99,80 & 101,05 & $\hat{\mathrm{Y}}=100,72$ \\
\hline & $\mathrm{DE}(E D)$ & 56,88 & 58,30 & 58,06 & 57,13 & 53,69 & $\hat{Y}=56,81$ \\
\hline & $\mathrm{a}$ & 17,30 & 17,34 & 17,94 & 17,92 & 17,78 & $\hat{Y}=17,66$ \\
\hline & b & 83,68 & 83,94 & 84,87 & 80,10 & 83,17 & $\hat{\mathrm{Y}}=83,15$ \\
\hline PB Fubá de milho & $c^{16}$ & 4,79 & 4,41 & 4,91 & 4,95 & 5,67 & $\hat{\mathrm{Y}}=4,95$ \\
\hline CP corn & $\mathrm{i}^{7}$ & $-0,98$ & $-1,28$ & $-2,81$ & 1,98 & $-0,95$ & $-0,81$ \\
\hline \multirow[t]{2}{*}{ ground grain } & $\mathrm{DP}(P D)$ & 100,98 & 101,28 & 102,81 & 98,02 & 100,95 & $\hat{\mathrm{Y}}=100,81$ \\
\hline & $\mathrm{DE}(E D)$ & 48,10 & 49,05 & 53,23 & 50,95 & 55,13 & 1 \\
\hline PB feno de capim & $\mathrm{a}$ & 14,19 & 13,58 & 12,79 & 15,62 & 14,76 & $\hat{\mathrm{Y}}=4,19$ \\
\hline coast-cross & b & 39,60 & 47,62 & 35,97 & 34,27 & 26,00 & 2 \\
\hline CP Coast cross & $c^{6}$ & 3,35 & 3,41 & 4,10 & 3,46 & 4,98 & 3 \\
\hline \multirow[t]{3}{*}{ grass hay } & $\mathrm{i}$ & 46,20 & 38,79 & 51,24 & 50,10 & 59,24 & 4 \\
\hline & $\mathrm{DP}(P D)$ & 53,80 & 61,21 & 48,76 & 49,89 & 40,76 & 5 \\
\hline & $\mathrm{DE}(E D)$ & 32,63 & 31,56 & 30,41 & 30,16 & 29,04 & $\hat{Y}=30,76$ \\
\hline
\end{tabular}

1. $\hat{Y}=44,9103+0,1064^{*} \mathrm{C}, r^{2}=0,75 ; 2 . \hat{\mathrm{Y}}=52,9181-0,2704^{*} \mathrm{C}, \mathrm{r}^{2}=0,66 ; 3 . \hat{\mathrm{Y}}=2,5270+0,02221^{*} \mathrm{C}, \mathrm{r}^{2}=0,57$; 4. $\hat{\mathrm{Y}}=34,1596+0,2493^{*} \mathrm{C}, \mathrm{r}^{2}=0,63 ; 5 . \hat{\mathrm{Y}}=65,8404-0,2493^{*} \mathrm{C}, \mathrm{r}^{2}=0,63 ; 6 . \% / \mathrm{h} ; 7$. Valores negativos correspondem à estimativa zero (Negatives values correspond to zero estimate); ${ }^{*}(\mathrm{P}<0,05)$ pelo teste $\mathrm{F}$ (by $\mathrm{F}$ test); e $\mathrm{C}=$ Nível de concentrado nas dietas experimentais (Concentrate levels in the experimental diets). 


\section{Conclusões}

A taxa de passagem de fluidos no rúmen-retículo apresentou comportamento quadrático, estimandose o valor máximo de $9,73 \%$ /h, com o nível de $61,99 \%$ de concentrado.

A taxa de passagem de partículas do farelo de soja no rúmen-retículo diminuiu linearmente, enquanto no ceco-cólon proximal não foi influenciada pelo aumento no nível de concentrados.

As taxas de passagem de partículas do feno de capim coast-cross no rúmen-retículo e no cecocólon proximal não foram influenciadas pelo aumento do nível de concentrados.

A degradabilidade efetiva da MS do farelo de soja não foi influenciada pelos níveis de concentrado, enquanto que a do fubá de milho aumentou linearmente e a do feno de capim coast-cross reduziu linearmente.

A degradabilidade efetiva da PB do farelo de soja e do feno de capim coast-cross não foi influenciada pelos níveis de concentrado, ao passo que a do fubá de milho aumentou linearmente.

\section{Referências Bibliográficas}

AGRICULTURAL RESEARCH COUNCIL - ARC. 1984. The nutrient requirements for ruminant livestock. London: CAB. 45p. (Suppl. 1).

ANDRADE, P. Técnica in situ (saco de náilon) na avaliação de alimentos para ruminantes. In: SIMPÓSIO INTERNACIONAL DE PRODUÇÃO DE RUMINANTES, REUNIÃO ANUAL DA SOCIEDADE BRASILEIRA DE ZOOTECNIA, 31, 1994, Maringá. Anais... Maringá: Eduem, 1994, p. 141-147.

AROEIRA, L.J.M., LOPES, F.C.F., DAYRELL, M.S. 1996. Degradabilidade de alguns alimentos no rúmen de vacas Holandês/Zebu. R. Soc. Bras. Zootec., 25(6):1178-1186.

BERCHIELLI, T.T. Efeito da relação volumoso:concentrado sobre a partição da digestão, a síntese de proteína microbiana, produção de ácidos graxos voláteis e desempenho de novilhos em confinamento. Belo Horizonte: UFMG, 1994. 103p. Tese (Doutorado em Ciência Animal) - Universidade Federal de Minas Gerais, 1994.

BRODERICK, B.A. Methodology for determining ruminal degradability of feed proteins. In: Pereira, J.C.(Ed.) SIMPÓSIO INTERNACIONAL SOBRE EXIGÊNCIAS NUTRICIONAIS DE RUMINANTES, 1995, Viçosa, MG, 1995. Anais... Viçosa, MG, 1995. p.139-176.

BÜRGER, P.J., PEREIRA, J.C., COELHO DA SILVA, J.F. et al. 2000. Consumo e digestibilidade aparente total e parcial em bezerros holandeses alimentados com dietas contendo diferentes níveis de concentrado. Rev. bras. zootec., 29(1):206214.

CAREY, D.A., CATON, J.S., BIONDINI, M. 1993. Influence of energy source on forage intake, digestibility, in situ forage degradation, and ruminal fermentation in beef steers fed medium-quality brome hay. J. Anim. Sci., 71(8):2260-2269.

CARVALHO, A.U., VALADARES FILHO, S.C., COELHO DA SILVA, J.F. et al. 1997. Níveis de concentrado em dietas de zebuínos. 4. Concentrações ruminais de amônia e pH, taxa de passagem da digesta ruminal e degradação in situ dos alimentos. R. Bras. Zootec., 26(5):1016-1024.

CECAVA, M.J., PARKER, J.E. 1993. Intestinal supply of amino acids in steers fed ruminally degradable and undegradable crude protein sources alone and in combination. J. Anim. Sci., 71(6):1596-1605

CHATURVEDI, O.H., WALLI, T.K. 1995. Ruminal dry matter and protein degradability of some concentrate ingredients using nylon bag technique. Ind. J. Anim. Sci., 12(3):133-139.

COLEMAN, S.W., EVANS, B.C., HORN, G.W. 1984. Some factors influencing estimates of digesta turnover rate using markers. J. Anim. Sci., 58(4):979-986.

COLUCCI, P.E. Comparative digestion and digesta kinetics in sheep and cattle. Guelph:University of Guelph, 1984, 221p. Thesis (Ph.D. Thesis Animal Science) - University of Guelph, 1984.

COLUCCI, P.E., MACLEOD, G.K., GROVUM, W.L., et al. 1990. Digesta kinetics in sheep and cattle fed diets with different forage to concentrate ratios at high and low intakes. J. Dairy Sci., 73(8):.2143-2156.

DESCHAMPS, F.C. 1994. Degradabilidade ruminal da matéria seca e da proteína de alguns alimentos utilizáveis na alimentação de ruminantes. R. Soc. Bras. Zootec., 23(6):898-908.

ELLIS, W.C., MATIS, J.H., POND, K.R. et al. 1984. Dietary influences on flow rate and digestive capacity. In: GILCHRIST, F.M.C., MACKIE, R.I. (Eds.). Herbivore nutrition in the subtropics and tropics. Pretoria: Science Press., p.269-293.

EVANS, E. 1981. An evaluation of the relationhips between dietary parameters and rumen turnover rate. Can. J. Anim. Sci., 61(1):91-96.

FIRKINS, J.L., BERGER, L.L., MERCHEN, N.R. et al. 1986. Effects of forage particle size, level of feed intake and supplemental protein degradability on microbial protein sinthesys and site of nutrient digestion in steers. J. Anim. Sci., 62(4):1081-1094.

GALLOWAY, D.L., GOETSCH, A.L., FORSTER, L.A. et al. 1993. Feed intake and digestibility by cattle consuming bermudagrass or orchardgrass hay supplemented with soybean hulls and (or) corn. J. Anim. Sci., 71(11):3087-3095.

GOETSCH, A.L., GALYEAN, M.L. 1982. Effect of dietary concentrate level on rumen fluid dilution rate. Can. J. Anim. Sci. , 62(2):649-652.

GOMES, S.Z. Digestão parcial e total da proteína e energia e cnsumo voluntário da MS por diferentes grupos genéticos de bovídeos. Viçosa, MG: UFV, 1982. 106p. Dissertação(Mestrado em Zootecnia) - Universidade Federal de Viçosa, 1982.

GROVUM, W.L., WILLIAMS, V.J. 1973. Rate of passage of digesta in sheep. 4. Passage of marker through the alimentary tract and the biological relevance of rate-constants derived from the changes in concentration of marker in faeces. $B r . J$. Nutr., 30(2):313-329.

GUNTER, S.A., KRYSL, L.J., JUDKINS, M.B. et al. 1990. Influence of branched-chain fatty acid supplementation on voluntary intake, site of digestion, ruminal fermentation, digesta kinetics and microbial protein sinthesys in beef heifers consuming grass hay. J. Anim. Sci., 68(9):2885-2892.

HESS, B.W., KRYL, L.L., JUDKINS, M.B. et al. 1996. Supplemental cracked corn or wheat bran for steers grazing endophytefree, particulate anf fluid kinetics, ruminal fermentation, and digestion. J. Anim. Sci., 74(5):1116-1125.

HUHTANEN, P., KUKKONEN, U. 1995. Comparison of methods, markers, sampling sites and models for estimating digesta passage kinetics in cattle fed at two levels of intake. 
Anim. Feed Sci. Technol., 52(1/2):159-173.

JONES, A.L., GOESTCH, A.L., STOKES, S.R. et al. 1988. Intake and digestion in cattle fed warm-or cool-season grass hay with or without supplemental grain. J. Anim. Sci., 66(1):194-203.

LALLES, J.P., DELVAL, E., PONCET, C. 1991. Mean retention time of dietary residues within the gastrointestinal tract of the young ruminant: a comparison of non-compartmental (algebraic) and compartmental (modelling) estimation methods. Anim. Feed Sci. Technol., 35(1/2):139-159.

LALLES, J.P., PONCET, C. 1990. Rate of passage of digesta during and after weaning in calves fed concentrate diets containing pea or soya-bean meal. Lvstck. Prod. Sci., 24(4):333-345.

LARDY, G.P., CATLETT, G.E., KERLEY, M.S. et al. 1993. Determination of the rumen escape value and duodenal amino acid flow of rapeseed meal. J. Anim. Sci., 71(11):3096-3104.

LOPEZ-GUISA, J.M., SATTER, L.D. 1991. Effect of forage source on retention of digesta markers applied to corn gluten meal and brewers grains for heifers. J. Dairy Sci., 74(12):4297-4304.

MAENG, W.J., BALDWIN, R.L. 1976. Dynamics of fermentation of purified diet and microbioal growth in the rumen. J. Dairy Sci., 59(4):636-642.

MASOERO, F., FIORENTINI, L., ROSSI, F. et al. 1994. Determination on nitrogen intestinal digestibility in ruminants. Anim. Feed Sci. Technol., 48(3/4):253-263.

MEHREZ, A.Z., ØRSKOV, E.R. 1977. A study of the artificial bag technique for determining the digestibility of feeds in the rumen. J. Agric. Sci., 88(3):645-650.

MICHALET-DOREAU, B., PHILIPPEAU, C., DOREAU, M. 1997. In situ and in vitro ruminal starch degradation of untreated and formaldehyde-treated wheat and maize. Reprod. Nutr. Dev., 37(3):305-312.

MIRON, J., SOLOMON, R., BRUCKENTAL, I. et al. 1996. Effect of changing the proportion wheat:sorghum in dairy cow rations on carbohydrate digestibility and NAN flow to the intestine. Anim. Feed Sci. Tchnol., 57(1/2):75-86.

MOLONEY, A.P., WILSON, R.K., MOLONEY, B.C. 1994. Rumen fermentation and digesta passage in ruminants fed cimanterol. Anim. Feed. Sci. Technol., 46(3/4):215-227.

NATIONAL RESEARCH COUNCIL - NRC.1996. Nutrient requirements of beef cattle. Washington, D.C.: Nacional Academy of Sciences. 242p.

NATIONAL RESEARCH COUNCIL - NRC.1989. Nutrient requirements of dairy cattle. Washington, D.C.: Nacional Academy of Sciences. 157p.

NATIONAL RESEARCH COUNCIL - NRC.1985. Ruminant nitrogen usage. Washington, D.C.: Nacional Academy of Sciences. 138p.

NOCEK, J.E. 1988. In situ and other methods to estimate ruminal digestion and energy digestibility: A review. J. Dairy Sci., 71(8):2051-2069.

ØRSKOV, E.R., McDONALD, I. 1979. The estimation of protein degradability in the rumen from incubation measurements weighted according to rate of passage. J. Agric. Sci., 92(2):499-503.
OSPINA, H. Influência do nível de consumo de feno sobre a digestibilidade, cinética digestiva e degradação ruminal em bovinos. Porto Alegre:UFRGS, 1995. 249p. Tese (Doutorado em Zootecnia) - Universidade Federal do Rio Grande do Sul, 1995.

OWENS, F.N., GOETSCH, A.L. 1988. Ruminal fementation. In: CHURCH, D.C. (Ed.). The ruminant animal digestive physiology and metabolism. New Jersey: Prentice Hall, p.145-171.

PEREIRA, J.C. Degradación ruminal de diversos subproductos agroindustriales. Madrid: UPM, 1992, 223p. Thesis (Doctorado en Producción Animal) - Universidad Politécnica de Madrid, 1992.

PEYRAUD, J.L., LIBOUX LE, S., VÉRITÉ, R. 1997. Effect du niveau de nature de l'azote dégradable sur la digestion ruminale d'un régime à base d'ensilage de maïs chez la vache laitière. Reprod. Nutr. Dev., 37(3):313-328.

SILVA, D.J. 1990. Análise de alimentos (Métodos químicos e biológicos). 2.ed. Viçosa, MG: UFV.165p.

STATSOFT. 1995. Statistica for Windows. Release 5.0 A [Computer program manual]. Tulsa. (CD-Rom).

UDÉN, P., COLUCCI, P.E., VAN SOEST, P.J. 1980. Investigation of chromium, cerium and cobalt as markers in digesta rate of passage studies. J. Sci. Food Agric., 31(6):625-632.

UNIVERSIDADE FEDERAL DE VIÇOSA. 1997. SAEG - Sistema de análises estatísticas e genéticas. Versão 7.1.Viçosa, MG. 150p. (Manual do usuário).

VALADARES FILHO, S.C., COELHO DA SILVA, J.F., LEÃO, M.I. 1990. Degradabilidade in situ da matéria seca e proteína bruta de vários alimentos em vacas em lactação. R. Soc. Bras. Zootec., 19(6):513-522.

VAN SOEST, P.J. 1994. Nutritional ecology of the ruminant. 2.ed. Ithaca: Cornell. 476p.

VILELA, G.L. Degradabilidade "in situ" da matéria seca e da proteína bruta de vários alimentos em vacas alimentadas com diferentes rações. Viçosa, MG: UFV, 1994, 68p. Dissertação (Mestrado em Zootecnia) - Universidade Federal de Viçosa, 1994.

WILliAMS, C.H, DAVID, D.J., IISMAA, O. 1962.The determination of chromic oxide in faeces samples by atomic absoption spectrophotometry. J. Agric. Sci., 59(3):381-385.

Recebido em: 01/03/99

Aceito em: 02/08/99 